\title{
Containerless Processing Studies in the MSFC Electrostatic Levitator
}

\author{
J. R. Rogers ${ }^{1}$ and M. P. SanSoucie ${ }^{2}$ \\ NASA Marshall Space Flight Center, Huntsville, AL, 35812
}

\begin{abstract}
Levitation or containerless processing represents an important tool in materials research. Levitated specimens are free from contact with a container, which permits studies of deeply undercooled melts, and high-temperature, highly reactive materials. Containerless processing provides data for studies of thermophysical properties, phase equilibria, metastable state formation, microstructure formation, undercooling, and nucleation. Levitation techniques include: acoustic, aero-acoustic, electromagnetic, and electrostatic. In microgravity, levitation can be achieved with greatly reduced positioning forces. Microgravity also reduces the effects of buoyancy and sedimentation in melts. The European Space Agency (ESA) and the German Aerospace Center (DLR) jointly developed an electromagnetic levitator facility (MSL-EML) for containerless materials processing in space. The MSL-EML will be accommodated in the European Columbus Facility on the International Space Station (ISS). The electrostatic levitator (ESL) facility at the Marshall Space Flight Center provides support for the development of containerless processing studies for the ISS. The capabilities of the facility and recent results will be discussed.
\end{abstract}

\section{Introduction}

$\mathrm{T}_{\mathrm{n}}$ he MSFC electrostatic levitation (ESL) facility utilizes non-contact measurement methods to provide materials property and processing data. Properties include: creep strength, thermal expansion/density, emissivity, specific heat and phase diagrams as well as surface tension as viscosity for melts. An additional advantage of this containerless method is that these measurements can be performed on a single sample. Processing melts in a container can impair access to metastable states and deep undercooling due to contamination. Containerless methods such as electrostatic levitation represent a novel approach to high temperature materials property measurement as well as the study of deeply undercooled melts and metastable states. Electrodes are used to position the sample free from contact with a container during measurements ${ }^{1}$. The technique can be used to process a wide variety of materials including metals, alloys, ceramics, glasses and semiconductors ${ }^{2}$. Samples are typically spherical and range from 2-3 $\mathrm{mm}$ diameter and 30-70 $\mathrm{mg}$. Specimens have been fabricated by arc melting, machining, hydraulic pressing, and laser melt. YAG, $\mathrm{CO} 2$ and solid state lasers are available for heating samples. The MSFC ESL was developed to process materials under a broad range of conditions from $10^{-8}$ Torr to 5 atm. Since its inception in 1997, the facility has successfully levitated and processed hundreds of samples. Data sets from thousands of melt cycles have been delivered to customers, including Principal Investigators from numerous NASA peer-reviewed projects. The MSFC ESL facility is now available to external customers on a cost-reimbursable basis.

The ESL facility provides support to the containerless processing community of NASA's Physical Science Program. This program supports scientific investigations that will be performed on the International Space Station (ISS). Scientific topics which can be investigated include metastable state formation, undercooling, nucleation, phase equilibria, solidification and other aspects of materials processing and characterization. Containerless process in the reduced gravity environment provides several advantages. On Earth, the effects of buoyancy and sedimentation are still present in the sample and can impair some types of studies. Strong positioning forces are required to levitate specimens in the ground-based lab. The required positioning forces are greatly reduced in space, providing access to additional experimental conditions. The European Space Agency (ESA) and the German Aerospace Center (DLR) supported the development of a containerless processing system for the ISS: an

\footnotetext{
${ }^{1}$ Assistant Chief, Environmental Effects Branch/EM50, AIAA Member

${ }^{2}$ Physicist, Environmental Effects Branch/EM50, not an AIAA Member.
} 
electromagnetic levitator (EML) ${ }^{3}$. The EML will be accommodated in the European Drawer Rack of the Columbus module of the ISS. EML samples include metals and alloys ranging from 5-8 $\mathrm{mm}$ in diameter.

\section{MSFC ESL Facility}

The ESL Facility includes a processing chamber that can be operated in either at $10^{-8}$ Torr or at pressures up to 3800 Torr. Figure 1 shows a schematic of the ESL system. The chambers are equipped with sample load locks and carousel mechanisms to permit high throughput sample processing. Sample heating systems include a $200 \mathrm{~W}$ continuous wave Nd:YAG and a $300 \mathrm{~W} \mathrm{CO}_{2}$ laser. A Phantom V7 camera provides 12 bit monochromatic images with 800x600 pixel resolution at rates up to 160,000 frames per second. The Redlake Motion Pro Model 10,000 provides 8 bit monochromatic images with 1280x1024 pixel resolution at rates up to 10,000 frames per second. Optical viewports are available on the chambers for user-provided equipment. An arc melter and a hydraulic press are available for sample fabrication. Sample etching and cleaning can be performed in the fume hood. Mass scales with 1 microgram resolution are available for pre- and post-process weighing to determine mass losses. Additional capabilities include residual gas analysis and infrared imaging. To date, the maximum temperature used for sample processing is $3400{ }^{\circ} \mathrm{C}$. Additional information about the MSFC ESL can be found at http://esl.msfc.nasa.gov/.

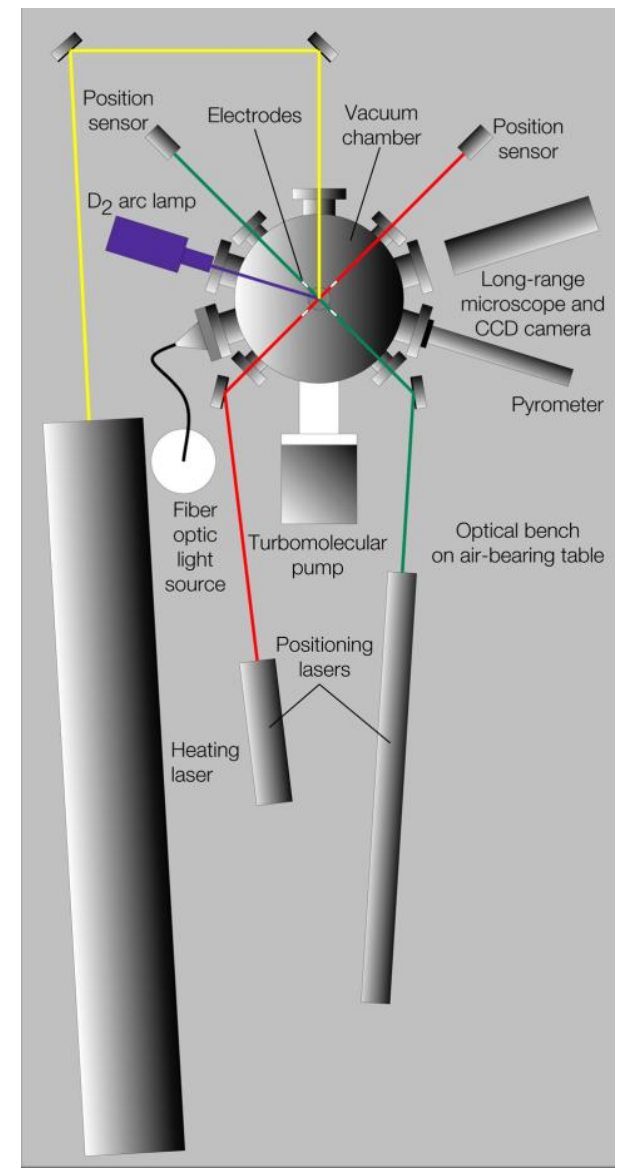

Figure 1. Schematic of ESL system.

The MSFC ESL facility has a new instrument for the determination of emissivity for heated samples in vacuum, using a blackbody source and a Fourier Transform Spectrometer, shown in Figure 2. AZ Technology Inc. has developed the instrument, designed to provide emissivity measurements for samples during levitation experiments over the temperature range 700-3500K. Detectors in a Nicolet 6700 FT-IR spectrometer measure emittance over the 
spectral range of 0.4-28 $\mu \mathrm{m}$. Emitted energy from the specimen and output from a Mikron M390S blackbody source at the same temperature with matched collection geometry are measured. Integrating emittance over the spectral range yields the total emittance. The ratio provides a direct measure of total hemispherical emittance. Optical filters prevent interference from the ESL system lasers.
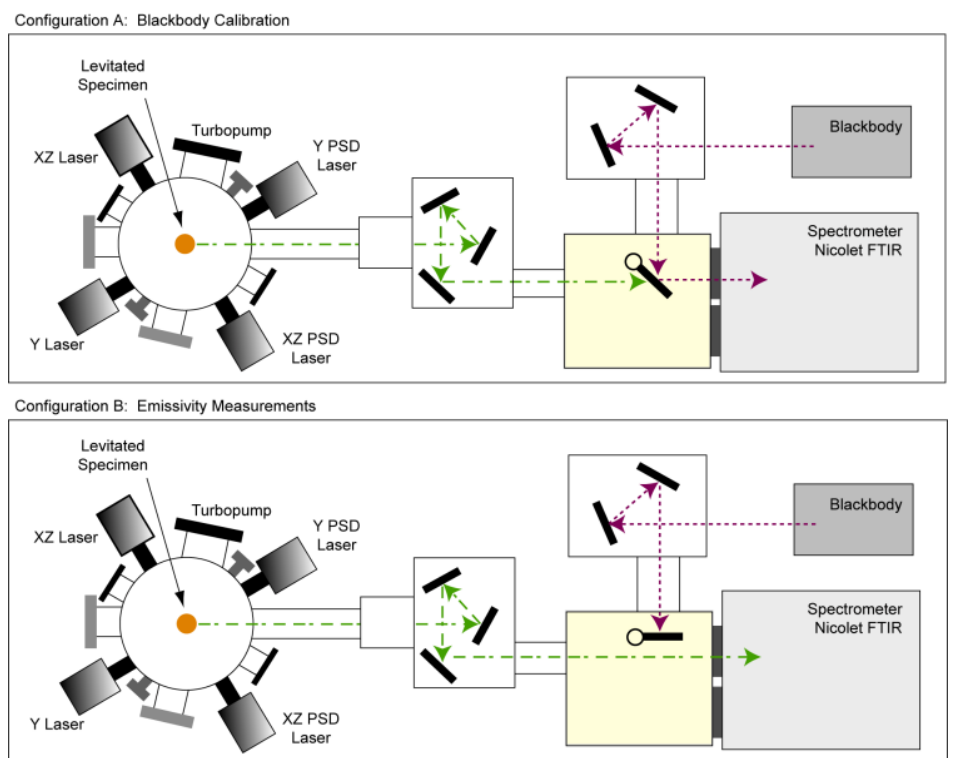

Figure 2. Schematic of the ESL system configured for emissivity measurements.

MSFC ESL capabilities include a portable apparatus: the Beamline ESL (BESL) apparatus ${ }^{4}$. The MSFC BESL was used for the first-ever ESL processing to be combined with a synchrotron $\mathrm{x}$-ray source for in-situ determination of the structure of liquid, transient, and stable phases. Research using the BESL for investigators from Washington University ${ }^{5}$ was selected as Editor's Choice for Science ${ }^{6}$ and was featured on the cover of Physics Today ${ }^{7}$. Recent work by Mauro and Kelton have developed a more modular BESL ${ }^{8}$.

The ESL laboratory has a Mikron M390S blackbody source, which operates at temperatures between 600 and $3000^{\circ} \mathrm{C}$. The unit provides an emissivity of 0.995 and a temperature accuracy of $\pm 0.25 \%$ for accurate calibration of optical pyrometers. For temperatures below $600{ }^{\circ} \mathrm{C}$, other lower-temperature blackbody sources are available at MSFC. A mounting flange permits attachment of components, which will be in the optical path of the pyrometer. Calibration can correct for losses due to transmission through ports, gas environments, and filters.

Pyrometers available for non-contact temperature measurement and are listed in Tables 1 and 2. In addition, the ESL facility has two multi-wavelength spectropyrometers. The FAR Associates FMP2X Expert System Multiwavelength Pyrometer is a non-contact temperature measuring devices with a range of $800-4000{ }^{\circ} \mathrm{C}$. Additionally, a FAR Associates FMP1 system is available, with a range of $300-2000{ }^{\circ} \mathrm{C}$. The multi-wavelength spectropyrometers provide temperature measurements with no operator input, even when the target's surface characteristics change with temperature or processing. The units are fiber-optic based, terminating onto a flat-field spectrograph using a concave holographic grating spanning 500 to $1000 \mathrm{~nm}$. A multi-element diode device detects the dispersed light. The device is calibrated with all intermediate optics using a standard lamp or a blackbody source at a single, welldefined temperature; then, the device is checked at temperatures throughout the range. 
Table 1. Single wavelength/band pyrometers available at the MSFC ESL.

\begin{tabular}{|l|l|c|c|c|}
\hline $\begin{array}{l}\text { Model } \\
\text { Impac/Mikron }\end{array}$ & $\begin{array}{l}\text { Temperature } \\
\text { Range }\left({ }^{\circ} \mathrm{C}\right)\end{array}$ & $\begin{array}{l}\text { Wavelength } \\
(\mu \mathrm{m})\end{array}$ & \multicolumn{2}{|c|}{$\begin{array}{l}\text { Response Times } \\
t_{90}(\mathrm{msec})\end{array}$} \\
\cline { 3 - 5 } & & & Digital & Analog \\
\hline IGA 100 & $200-1300$ & $1.45-1.8$ & 12.5 & 1.0 \\
\hline IGA 100 & $300-2500$ & $1.45-1.8$ & 12.5 & 1.0 \\
\hline MI-GA 140 & $350-2500$ & $1.45-1.8$ & 2.1 & 0.5 \\
\hline IS 120 & $1100-3500$ & 0.676 & 12.5 & 1.0 \\
\hline IGA 120 & $350-2400$ & $1.45-1.8$ & 12.5 & 1.0 \\
\hline IGA 120 & $350-2400$ & $1.45-1.8$ & 12.5 & 1.0 \\
\hline IE 120/8 & $500-2500$ & 8.0 & 12.5 & 5.0 \\
\hline
\end{tabular}

Table 2. Two-wavelength pyrometers available at the MSFC ESL.

\begin{tabular}{|l|l|l|c|c|}
\hline Model & $\begin{array}{l}\text { Temperature } \\
\text { Range }\left({ }^{\circ} \mathrm{C}\right)\end{array}$ & $\begin{array}{l}\text { Wavelengths } \\
(\mu \mathrm{m})\end{array}$ & \multicolumn{2}{|c|}{$\begin{array}{l}\text { Response Times } \\
t_{90}(\mathrm{msec})\end{array}$} \\
\cline { 3 - 5 } & & & Digital & Analog \\
\hline Modline-R & $1500-3500$ & $\sim 0.95, \sim 1.08$ & NA & 10 \\
\hline Mirage-OR & $700-1400$ & $\sim 0.95, \sim 1.08$ & NA & 10 \\
\hline
\end{tabular}

\section{Results and Discussion}

The MSFC ESL supports ISS investigations by using existing levitation hardware and capabilities to provide data for scientists. The MSFC ESL has unique ESL capabilities, including triggered nucleation, which is also available in the EML. The facility can provide ground-based support for scientists to help develop experiments. Preflight and post-flight studies can be performed to help understand flight results and define experiment conditions. This data can help PI's define science requirements, benefit experiment preparation and optimize science return. Results for selected ESL processing studies are presented below. A recent review provides additional details about materials processing and characterization in $\mathrm{ESL}^{2}$.

Thermophyscial property data are important for modeling behavior in melts. The MSFC ESL can provide this data. For example, density as a function of temperature is needed to model fluid flows. The measurement of density and thermal expansion can also be performed in the $\mathrm{ESL}^{9}$. The non-contact density measurement methods employed in ESL provide a resolution of approximately 300 parts per million, and are comparable to the best contact methods. Video images are captured during a heating cycle. An image processing program detects the edges of the specimen and calculates volume. A least squares fit to a 6 th order Lengendre polynomial provides edge detection. Image data are correlated with pyrometry data. Samples are weighed before and after data collection. Sample density is calculated from the measured volume and mass, as a function of temperature. Figure 3 shows density of solid and liquid $\mathrm{Ti}_{39.5} \mathrm{Zr}_{39.5} \mathrm{Ni}_{21}$ obtained using this technique. Calibration checks are performed using precision WC-Co spheres, selected to match the diameter of the experimental specimens. Industrial Tectonics Inc. fabricated the calibration spheres to the specifications of American Bearing Manufacturers Association, Grade 3 (tolerances: 75 $\mathrm{nm}$ sphericity and $750 \mathrm{~nm}$ diameter). 


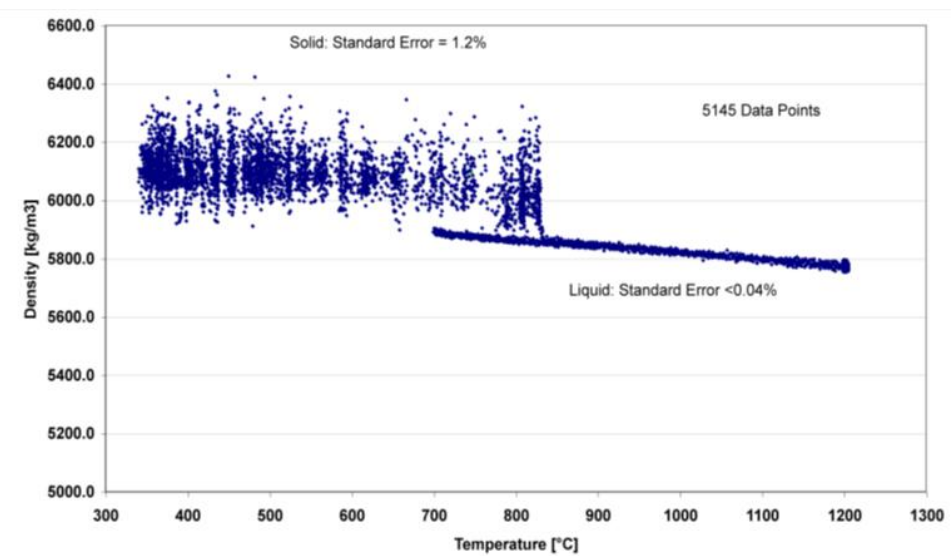

Figure 3. Density of solid and liquid $\mathrm{Ti}_{39.5} \mathrm{Zr}_{39.5} \mathrm{Ni}_{21}$.

A new technique for measuring creep deformation using the MSFC ESL has been developed ${ }^{10}$. This technique is based on electrostatic levitation of a spherical sample, heated to the measurement temperature and rotated at a rate such that the centrifugal acceleration causes creep deformation. Creep of samples has been demonstrated at up to $2300{ }^{\circ} \mathrm{C}$ in the MSFC ESL facility.

Triggered nucleation has been successfully performed at the ESL Facility. Electrostatic levitation allows for deep undercooling of samples. When a heterogeneous nucleation site is introduced a rapid solidification occurs. This allows the experimenter to study solidification velocities and grain growth characteristics as a function of undercooling. The heterogeneous nucleation point is a tungsten needle attached to a step-motorized linear translation vacuum feedthrough computer controlled by the user. This procedure has been used to study grain growth in triggered $\mathrm{Ni}_{60} \mathrm{Nb}_{40}$ samples ${ }^{11}$. Figure 4 shows a triggered nucleation sequence of $\mathrm{Ni}_{60} \mathrm{Nb}_{40}$ in the ESL Facility. The thin, tungsten needle enters from the left, touches the sample, and then retracts.

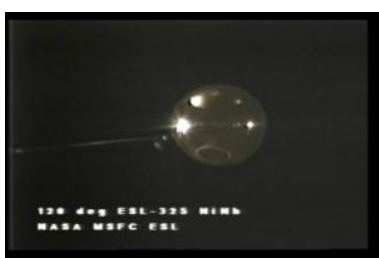

(a)

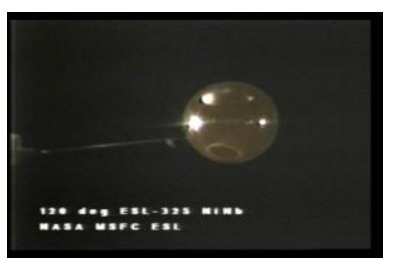

(b)

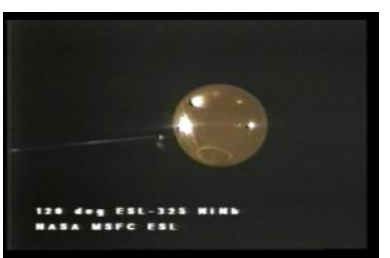

(c)

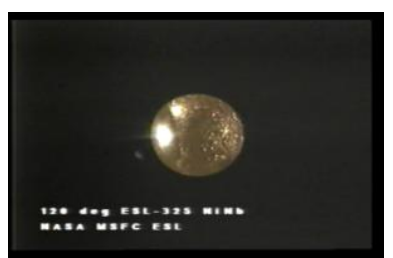

(d)

Figure 4. Triggered nucleation of $\mathrm{Ni}_{60} \mathrm{Nb}_{40}$ a) pre trigger, b) trigger, c) 1s post trigger, d) $15 \mathrm{~s}$ post trigger.

Studies with a transparent material such as lithium disilcate can illustrate the effects of gravity in the groundbased ESL. Containerless processing of inorganic oxide glass forming melts using the ESL have been successful. The glass forming tendancy of glasses of $\mathrm{Li}_{2} \mathrm{O} \cdot 2 \mathrm{SiO}_{2}\left(\mathrm{LS}_{2}\right)$ and $\mathrm{LS}_{2}$ doped with $0.001 \mathrm{wt} \%$ platinum have been studied at the ESL Facility ${ }^{12}$. It was shown that the glass forming tendencies when processed containerlessly are significantly increased compared to an identical melt in contact with a container.

Figure 5 depicts a $\mathrm{LiS}_{2}$ sample both fully melted and melted with crystallites. As can be seen in Figure $5 \mathrm{~b}$, sedimentation has occurred. In-space processing of these samples would mitigate the sedimentation. 


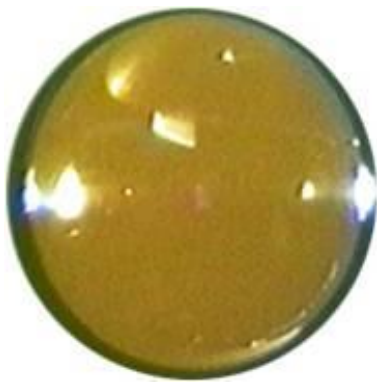

(a)

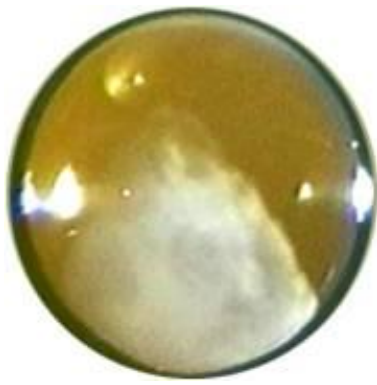

(b)

Figure 5. Lithim disilicate glass a) fully melted and b) melted with crystallites.

\section{ISS Investigations}

NASA scientists participate in the EML studies as members of ESA Topical Teams. These teams were formed to support scientists in establishing forums and collaborations focused on selected topics of interest to ESA. Each team is comprised of scientists from different countries with different viewpoints. Team members meet to exchange views and experience to collaborate on a common research theme. This concept allows scientists with similar interests and complementary expertise to develop flight research projects and enhance science return. For example, each EML sample may be studied by several Topic Team members, each specializing in a different aspect of the science, for example, fluid flow, thermophysical properties and nucleation behavior. The EML payload includes 18 samples per batch. The first batch includes samples that will be studied by NASA investigations supported by the MSFC ESL.

NASA PIs are members of the following ESA Topical Teams:

1. Thermophysical Properties of Liquid Metallic Alloys - Modelling of Industrial Solidification Processes and Development of Advanced Products (THERMOLAB-ISS)

2. Thermophysical properties and solidification behaviour of undercooled Ti-Zr-Ni liquids showing an icosahedral short-range order (ICOPROSOL)

3. Peritectic Alloy Rapid Solidification with Electromagnetic Convection (PARSEC)

List of PIs and their project titles:

1. Hyers, Robert, University of Massachusetts, "Unified Support for THERMOLAB-ISS, ICOPROSOL, and PARSEC"

2. Kelton, Ken, Washington University, "Studies of Nucleation and Growth, Specific Heat and Viscosity of Undercooled Melts of Quasicrystals and Polytetrehedral-Phase-Forming Alloys"

3. Kelton, Ken, Washington University, "NASA Research under ESA-Based Investigations THERMOLAB and ICOPROSOL"

4. Matson, Doug, Tufts University, "Electromagnetic Levitation Flight Support for Transient Observation of Nucleation Events" (ELFSTONE)

5. Matson, Doug, Tufts University, "Levitation Observation of Dendrite Evolution in Steel Ternary Alloy Rapid Solidification” (LODESTARS)

\section{Conclusion}

The MSFC ESL facility represents an important resource for the microgravity materials science research community. Results from the ESL facility are used in the development of experiments for containerless processing studies to be performed in the ESA's EML facility on the International Space Station (ISS). Future efforts may support ISS experiments using an Electrostatic Levitation System which has been proposed by NASDA ${ }^{13}$, the Japanese Space Agency. On-going activities include the development of a quench system to provide an additional capability to study microstructure development from melts. 


\section{Acknowledgments}

NASA's Physical Science Program provides support for the ESL facility's ISS-related studies. The materials science efforts for the program are implemented at the Marshall Space Flight Center.

\section{References}

${ }^{1}$ Rulison, A. J., Watkins, J. L., and Zambrano, B., "Electrostatic containerless processing system," Review of Scientific Instruments, Vol. 68, No. 7, 1977, pp. 2856-2863.

${ }^{2}$ Hyers, R. W., Rogers, J. R., “A Review of Electrostatic Levitation for Materials Research,” High Temperature Materials and Processes, Vol. 27, No. 6, 2008, pp. 461-474.

${ }^{3}$ Seidel, A., Soellner, W., and Stenzel, C., "EML - An Electromagnetic Levitator for the Internation Space Station," Journal of Physics: Conference Series, Vol. 327, 2011, pp. 2856-2863.

${ }^{4}$ Gangopadhyay, A. K., Lee, G. W., Kelton, K. F., Rogers, J. R., Goldman, A. I., Robinson, D. S., Rathz, T. J., and Hyers, R. W., "Beamline electrostatic levitator for in situ high energy x-ray diffraction studies of levitated solids and liquids," Review of Scientific Instruments, Vol. 76, No. 7, 2005, pp. 073901-073906.

${ }^{5}$ Kelton, K. F., Lee, G. W., Gangopadhyay, A. K., Hyers, R. W., Rathz, T. J., Rogers, J. R., Robinson, M. B., and Robinson, D. S., "First X-Ray Scattering Studies on Electrostatically Levitated Metallic Liquids: Demonstrated Influence of Local Icosahedral Order on the Nucleation Barrier," Physical Review Letters, Vol. 90, No. 19, 2003, pp. 195504.

${ }^{6}$ Physics Editor, “Editor's Choice for Physics Selection for Phys. Rev. Let. 90, 195504, May 2003” Science, May 30, 2003, pp. $1345-1346$.

${ }^{7}$ Day, C., "Experiments Vindicate a 50-Year-Old Explanation of How Liquid Metal Resists Solidification" Physics Today, June issue, 2003, pp. 24-26.

${ }^{8}$ Mauro, N. A., Kelton, K. F., "A highly modular beamline electrostatic levitation facility, optimized for in situ high-energy X-ray scattering studies of equilibrium and supercooled liquids," Review of Scientific Instruments, Vol. 82, No. 3, 2011, pp. 035114.

${ }^{9}$ Bradshaw, R., "Automatic Containerless Measurements of Thermophysical Properties of Quasicrystal Forming Melts," Ph.D. Dissertation, Mechanical and Industrial Engineering Dept., University of Massachusetts, Amherst, MA, 2006.

${ }^{10}$ Lee, J., Bradshaw, R., Hyers, R., Rogers, J. R., Rathz, T. J., Wall, J. J., Choo, H., and Liaw, P., "Non-contact measurement of creep properties of refractory materials," STAR, Vol. 44, No. 12, 2006.

${ }^{11}$ Rathz, T. J., Robinson, M. B., Hyers, R. W., Rogers, J. R., and Li, D., "Triggered nucleation in $\mathrm{Ni}_{60} \mathrm{Ni}_{40}$ using an electrostatic levitator," Journal of Materials Science Letters, Vol. 20, 2002, pp. 301-303.

${ }^{12}$ Ranasinghe, K. S., Ray, C. S., Day, D. E., Rogers, J. R., Hyers, R. W., Rathz, T., "Containerless processing of a lithium disilicate glass," Journal of Materials Science, Vol. 42, 2007, pp. 4291-4297.

${ }^{13}$ Paradis, P., Ishikawa, T., Watanabe Y., and Okada, J., "Hybrid Processing Combining Electrostatic Levitation and Laser Heating: Application to Terrestrial Analogues of Asteroid Materials," Advances in Optical Technologies, Vol. $2011,2002$. 